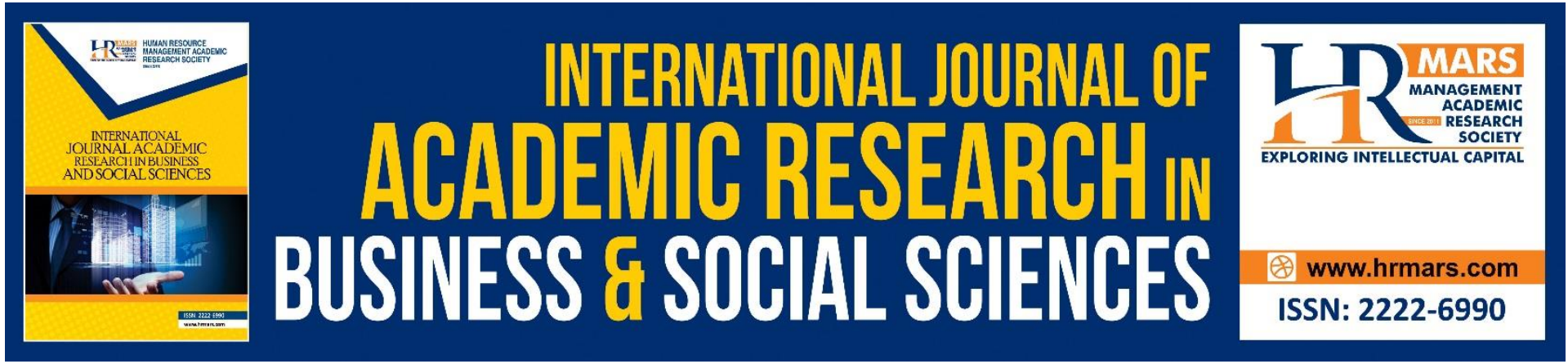

\title{
The Neural Correlates of Emotion in Decision-making
}

\section{Ahmed H. Alsharif, Nor Zafir Md Salleh and Rohaizat Baharun}

To Link this Article: http://dx.doi.org/10.6007/IJARBSS/v11-i7/10075

DOI:10.6007/IJARBSS/v11-i7/10075

Received: 06 May 2021, Revised: 10 June 2021, Accepted: 24 June 2021

Published Online: 04 July 2021

In-Text Citation: (Alsharif et al., 2021)

To Cite this Article: Alsharif, A. H., Salleh, N. Z. M., \& Baharun, R. (2021). The Neural Correlates of Emotion in Decision-making. International Journal of Academic Research in Business and Social Sciences, 11(7), 64-77.

\section{Copyright: @ 2021 The Author(s)}

Published by Human Resource Management Academic Research Society (www.hrmars.com)

This article is published under the Creative Commons Attribution (CC BY 4.0) license. Anyone may reproduce, distribute, translate and create derivative works of this article (for both commercial and non-commercial purposes), subject to full attribution to the original publication and authors. The full terms of this license may be seen at: http://creativecommons.org/licences/by/4.0/legalcode

Vol. 11, No. 7, 2021, Pg. 64 - 77

Full Terms \& Conditions of access and use can be found at http://hrmars.com/index.php/pages/detail/publication-ethics 


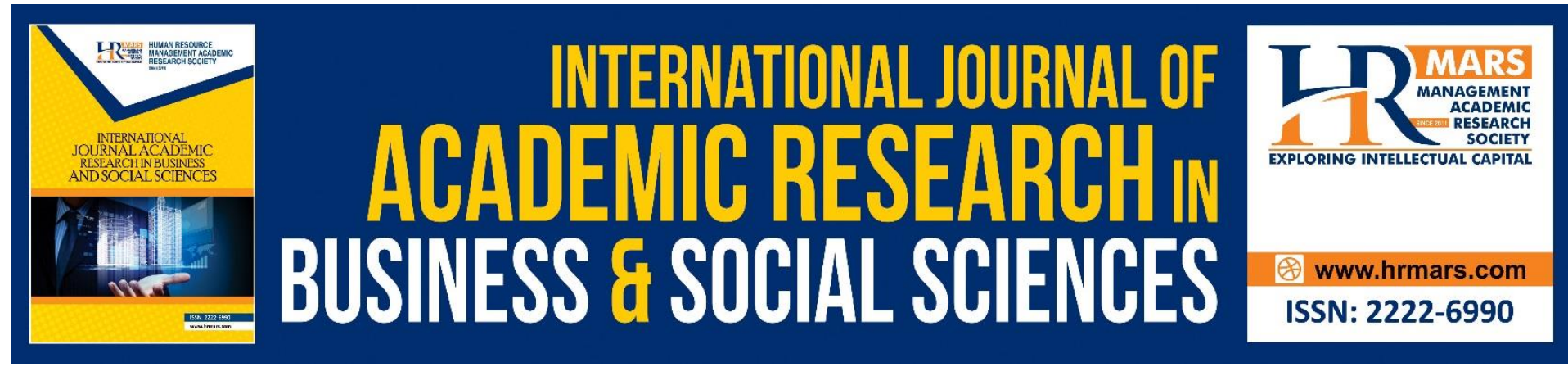

\title{
The Neural Correlates of Emotion in Decision- making
}

\author{
Ahmed H. Alsharif, Nor Zafir Md Salleh and Rohaizat Baharun \\ Azman Hashim International Business School (AHIBS), Universiti Teknologi Malaysia (UTM), \\ Skudai, Johor 81310, Malaysia \\ Email: ahmedalsharif07@gmail.com,zafir@utm.my,m-rohaizat@utm.my
}

\begin{abstract}
Both neuroscientific and psychology methods are used to study and explain the active neurons of the individuals' brain response when exposed to external stimuli. This study analyses the relevance literature and investigates the neural correlates of emotion, rewards, and motivation in the decision-making process, the emotional interactions between children, adolescents, and ageing. It was reviewed the literature to explore if neuroscientific methods provide accurate information about the role of emotion, reward, and motivation in decisionmaking mechanisms. The findings showed that the amygdala, medial prefrontal cortex, and ventromedial prefrontal cortex play a central role in processing of emotion which in turn influence decision-making process. While individuals with lesion in the ventromedial prefrontal cortex which is responsible for emotional responses toward risk, reward, and decision-making are not good decision-makers. In addition, the prefrontal cortex plays central role in approach and withdrawal motivational, whereby the right prefrontal cortex associated with withdrawal behavior and the left prefrontal cortex associated with approach behavior.
\end{abstract}

Keywords: Neuroscientific, Psychology, Neuroscience, Reward, Motivation, Emotion Interactions, Decision-Making, Age.

\section{Introduction}

Over the years, researchers and scientists were sought to explore what is inside individuals' brains and what they are thinking of (Alsharif, Salleh, Baharun, \& Safaei, 2020), to determine the subtle centers in the brain, which in turn lead them to make decisions. But with advent and advances of neuroscience tools, the study of individuals' brains has become increasingly significant (Alsharif et al., 2021), neuroscientific studies have shown that emotional processes such as emotions and feelings have highly impact on consumer behaviour (i.e., decision-making) not as was believed before. Feelings are relatively considered as conscious aspect of emotional states, such as the level of pleasure or unpleasure. At the same time, emotions are relatively an unconscious/ automatic somatic responses such as increase heart rate in a fighting/frightening condition and sweating (Dolcos \& Denkova, 2014; Siddharthan et al., 2018), which is significant to decision-making, learning, and problem solving (Gordon, 2006). There are several techniques to measure/record 
emotions (e.g., pupil dilation, sweating, neuroimaging techniques, ECG, breathing, and facial expressions) and feelings (e.g., self-report, survey, interviews, and focus groups).

In this study, we will focus on an unconscious aspect of emotional processes such as emotion. No doubt, the nature of emotion is still hotly debated (Alsharif, Salleh, \& Baharun, 2021; Barrett, 2017). For example, Ekman (2003) pointed out each emotion has a specific function which allows us to adapt to certain contexts. Additionally, supporters of " basic emotions" (i.e., fear, anger, sadness, disgust, joy, and surprise) pointed out that each one of those basic emotion has originated from a specific part of the brain with valence across species (Ekman, 1999; Tracy \& Randles, 2011). On the other side, the supporters of the "constructionist" assumed that the primary/basic emotions as a set of categories which do not create from their own concerned neural units, but they are constructed from a combination of activity in the brain which leads to psychological functions (e.g., memory and sensory perception) (Lisa Feldman Barrett, 2013). The concept of emotion has been described in a varied way by different authors, according to the theory they followed. For instance, $F$. Dolcos et al. (2019) proposed the definition of emotion as the individual's tendency to create, maintain, or terminate a relationship with the environment or with others (Frijda, 1986). According to (Damasio, 2003) neuroscience defined emotion as the set of physiological and brain changes as a resultant of the human responses based on the perceptions of human.

The emotions correspond with an individual's state, allowing for the emotional evaluation of the event, and because of this, the basic emotions are relatively constant for each individual (Lazarus, 2006). Therefore, the processing of emotional information can be both automatic, i.e., high emotional stimuli, and amendable, i.e., low emotional stimuli (Vuilleumier, 2005). It has found the activity in the amygdala (AMY) as a response to emotional stimuli; however, the medial prefrontal cortex (mPFC) and the ventromedial prefrontal cortex (VMPFC) associated with higher-level processing of emotion. In addition, it had shown amendable of emotional processes by attention when the attention resources were more available, besides, more time to perform the task (Shafer, lordan, Cabeza, \& Dolcos, 2011). Hence, emotions trigger a set of behavioral (e.g., run), physiological (e.g., sweat), and cognitive responses (e.g., evaluation of the event), and these changes allow an individual to deal with an event appropriately (Patrizia Cherubino et al., 2019a). Therefore, emotions provide an explanation of individuals' reactions, verbal reports, and conscious experiences (Kajic et al., 2019). Although we do not exactly realize the degree of our attraction or aversion toward something, the emotional signs provide feedback in our unconscious mind to quick and acceptable responses toward these things (e.g., people, pictures, ads, products, and so forth), where the acquired emotional signs from previous experiments led us for approaching or avoidance behaviour (Adolphs, 2017). However, there is a consensus on the two dimensions for measuring emotions: Arousal and Valence (Alsharif et al., 2021). Valence refers to either positivity or negativity responses such as please or unpleasure, respectively. Arousal refers to either high or low emotional arousal such as surprised and calmness, consecutively (Dolcos et al., 2019).

This research differs from review papers related to emotional processes in terms of this study discusses the vital role of emotion in influencing the decision-making process, the somatic sign hypothesis, the influence of rewards on emotion interactions, and individual differences in emotion interactions. To this end, this study tries to incorporate as many directions as possible, where popular research topics are investigated deeply based on their respective sub-domains to achieve a precise, concrete, and concise conclusion. 


\section{Emotional Regions in the Brain}

The neural substrates of emotions are distinguished of various famous discoveries, beginning with the exploration of the hypothalamus by the drawing of the Papez-circuit, and emphasizing on the amygdala importance in emotional reactions (Nábrády, 2005). The vital role of the amygdala in the processing of emotional functions and information has been proven by Jacobs et al (2012), thereby, the amygdala processes incoming emotional information and carries out automatic, unconscious, rapid emotional responses (Dolan \& Vuilleumier, 2003; Montazeribarforoushi, Keshavarzsaleh, \& Rams $\varnothing y, 2017$; Öhman, Carlsson, Lundqvist, \& Ingvar, 2007). In fact, the most important regions in the human brain when we are going to talk about emotions are the amygdala and hippocampus in the limbic system. The limbic system is considered as a middle layer of the brain and associated with controlling feelings of pleasure and pain. Wherein the amygdala plays a central role in responding to stimuli, while the hippocampus associated with memory creation in the short- and long-term (Chow et al., 2018; Montazeribarforoushi et al., 2017; Papez, 1937; Torrico \& Abdijadid, 2019). Therefore, this system is explaining the stimulus based on previous experience, thereby, give us guidelines on how ca deal with it. Consequently, it will determine if we should pay attention to the stimuli, whether it is good for us or not, and whether we should approach or avoidance (Genco, Pohlmann, \& Steidl, 2013).

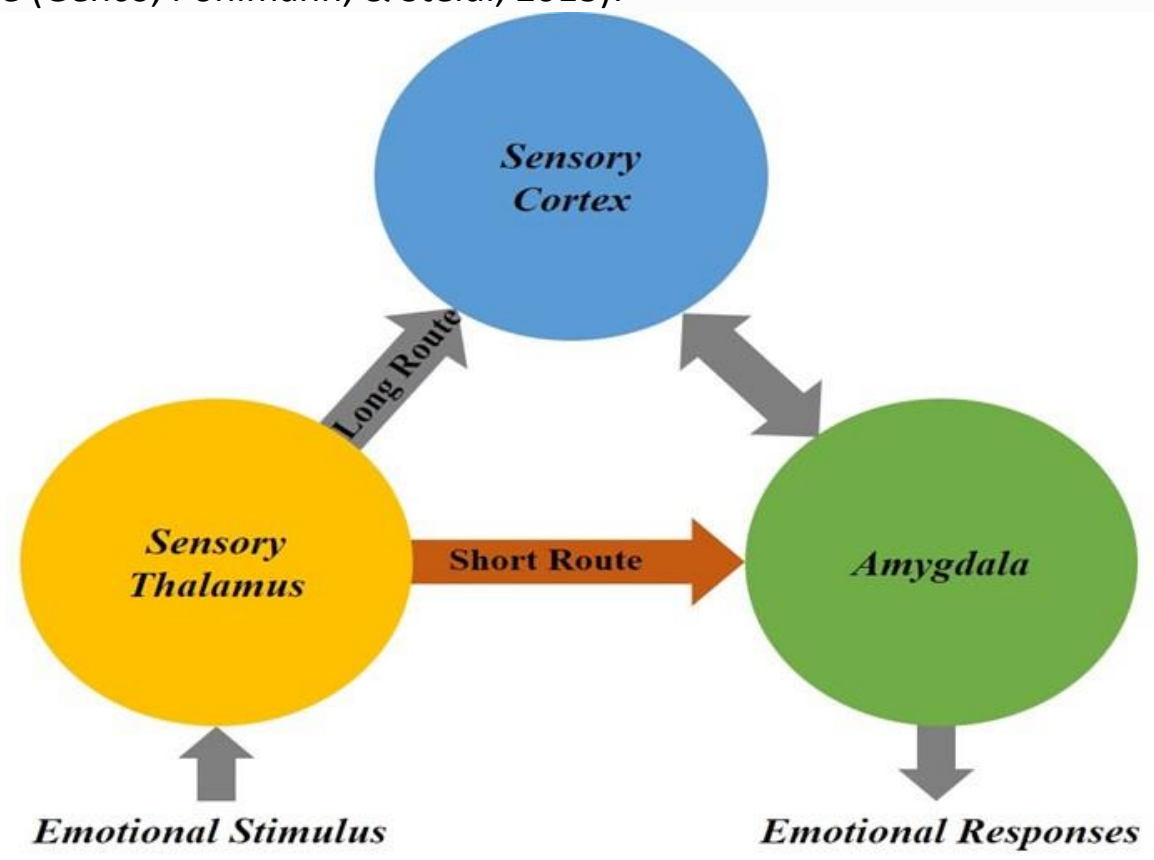

Fig. 1. Long and Short Route of the Emotional Responses (LeDoux, 1998).

LeDoux (1998) stated the model of flow information through the human brain goes to the amygdala by either the short or the long route (Figure 1) (Simson, 2010). For example, when we exposed to the stimulus, the stimulus goes to the sensory thalamus, then take either short route for quick reactions or long route for previous memories, then arrive to the amygdala, in turn, send emotional responses. In danger or frighten condition, individuals' reactions will take the short route to the amygdala which leads to some physiological changes such as sweating, increased heart rate, then prevent an individual to take this dangerous way. Thereafter, it will be sent information to AMY through the long-route to access memories in order to evaluate the situation and give a more informed response, this explains why we jump from our seats during watch horror film and after moments we realise there is no real danger. 
Naturally, the emotional flow demonstrates that our cognition is the last shelter which our brain resort to interpret and react to stimuli (Ramsoy, 2014; Simson, 2010).

\section{Decision Making Processes}

Many models and theories aimed to understand the making-decision process, through qualitative or quantitative research methods. Over time, market research has been focused on qualitative methods because researchers believe maybe these methods can help to reveal consumers' perceptions and motivations in decision-making processes (Eser, Isin, \& Tolon, 2011). According to (Page, 2012), the consumers do not fully realize what lead them in taking a particular decision, and it has discovered that the making-decision process is more complicated than we had realised. This lead to infer that several factors impact makingdecision processes as instinctive factors which have evolved from prior experiences. In the same sense, it is challenging to forecast these instinctive factors by traditional methods, thereby, neuroscience, neuromarketing, and psychology can give valuable add in determining these factors.

In the 1970s and 1980s, researchers began to reveal some decision-making methods, as studies were developed, indicating that the consumer might or not be involved in decisionmaking before the actual buying action, wherein this was explained through the lack of relevant information or override some important information by consumers because some consumers do not have enough experience to take a decision (Harrison, Waite, \& White, 2006). Daniel Kahneman has conducted some valuable research in decision making process in the brain in order to determine how consumers make decisions, it has concluded that people are not rational decision-makers, but instead, he used the term "bounded rationality". It has invented a brilliant model (system 1 and system 2) of making-decision mechanisms in the brain (Table 1). Accordingly, Kahneman won the Nobel Prize in 2002 for integrating the advances in psychological research with economic science and analyzed the complexity of individuals' thinking during making-decisions. This Kahneman's model is considered as the foundation to understanding the bias processes in the traditional marketing processes such as interviews, questionnaires, and focus groups and why neuromarketing emerged as an alternative. Traditional marketing studies have relied on "system 2" which supposed the rationality consumer - can describe their needs accurately and why to choose these specific products and services over others. On the contrary, neuromarketing has relied on neuroimaging tools which have proven the irrationality of the consumer in making-decisions, i.e., system 1; thereby, provide new insights to understand how and why consumer respond toward marketing stimuli and interact with markets (Kahneman, 2011).

Table 1.The Model of Decision-Making in the Human Brain.

\begin{tabular}{|l|l|}
\hline System $\mathbf{1}$ & System $\mathbf{2}$ \\
\hline Fast & Slow \\
\hline High Capacity & Low Capacity \\
\hline Unconscious & Conscious \\
\hline Implicit & Explicit \\
\hline Low Effort & High Effort \\
\hline Automatic & Controlled \\
\hline
\end{tabular}

Source: Adopted by Kahneman (2011). 
The decision-making model can be deemed as the form of problem recognition and problem-solving as depicted in Figure 2 illustrates that each stage in the model has a corresponding internal psychological process. Therefore, when we move to the second stage the way of motivation to solve a problem occurs, usually influences the following stages of the process (Belch \& Belch, 2007).

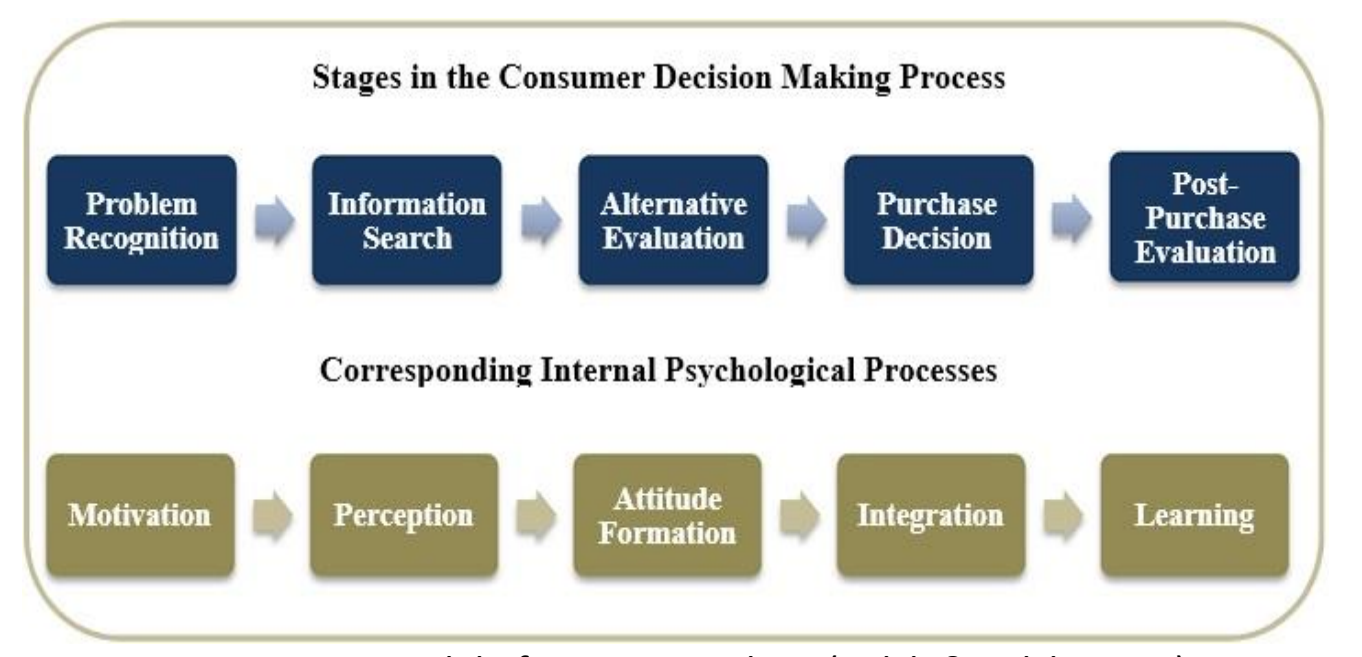

Fig. 2. Basic Model of Decision Making (Belch \& Belch, 2007).

That led to infer that the decision-making process is not only relying on economic or rational factors but also interactive with emotion, cognition, environment and social factors (Vermaak \& de Klerk, 2017). Therefore, there are essential factors which are playing a vital role in decision-making processes such as emotions, motivation, reward. That is the reason for orienting towards emotional studies (Agarwal, 2015; Hu \& Nasiry, 2018).

\section{Approach and Withdrawal Motivation}

Motivational and emotional processes are closely connected to each other (Lang \& Bradley, 2008). Motivational processes play a vital role in influencing the cognition and consumer behaviour (e.g., decision-making) (Chiew \& Braver, 2011; Pessoa, 2013). Unlike emotional processes, motivational process is driving force that is orienting consumers to engage in action/task, thereby, achieve their goals (Luiz Pessoa, 2009). Motivational state can drive emotion, attention, and their interactions (Luiz Pessoa, 2014; Raymond, 2009). Similar to the dimensions of valence, it has been used approach and withdrawal behaviour as dimensions of motivations (Cherubino et al., 2019b; Higgins, 1998). Therefore, marketers and advertisers have to well-study the consumer's motivational processes to direct the marketing mix to the target audience effectively (Bahrabad \& Farrokhian, 2017).

Contemporarily, researchers attempt to investigate brain activity signals correlated with an increase of emotional processes during the interaction with stimuli (Langleben et al., 2009; Vecchiato et al., 2010). The literature findings showed that the frontal cortex (FC) and prefrontal cortex (PFC) regions play a central role in emotional processing activity in the individual brain (Amthor, 2016; Davidson \& Irwin, 1999). According to asymmetry of the PFC structurally and functionally, the PFC play a vital role in generating emotions (Davidson, 2000). The experiment has been conducted to examine the role of PFC in approach and withdrawal motivational, and emotion by using the EEG technique. The findings showed that the anterior cerebral hemispheres play a central role in approach and withdrawal motivational and 
emotions, wherein the right PFC connected with withdrawal behavior (Davidson, 2004), while the left PFC is linked with approach behavior (Cherubino et al., 2015; Davidson, 2004).

\section{The Impact of Rewards and Risk on the Emotional Interactions}

It is important to know the brain regions that are triggered during attractive reward elements such as money (Knutson et al., 2001), food (Berridge, 1996), and social interactions (Lehner et al., 2017). Some studies have shown that incentives or positive reinforcement (i.e., gaining monetary or other forms of reward for correct performance) improve accuracy at task (Gilbert \& Fiez, 2004) and performance in cognitive tasks by modulating early attentional processes (Anderson, 2016; Krawczyk, Gazzaley, \& D'Esposito, 2007). For example, when the visual features of a stimulus are linked to a reward finding/outcome, they acquire high priority and can automatically grab visual attention (Anderson, Laurent, \& Yantis, 2013). In addition, design of product or brand preference can active the reward system in the individuals' brain, which might trigger the motivations and therefore, influence individuals' decisions ( $P$. Cherubino et al., 2019). Most evidence regarding emotion-attention interactions benefits from the impact of negative and positive emotional information, produced by motivational stimuli, wherein positive motivation is deemed as an effective method to urges and sustain/maintain goals, for example, when the individuals have been told that they will receive a reward for correct performance or when they expect a future reward (Chiew \& Braver, 2016). Similar to negative emotional motivation, rewards can contribute to distraction if these rewards have not corresponded with the task at hand (Brian August Anderson et al., 2013). But most studies focused on the individual's response to monetary rewards through approaching or avoidance behaviour (Case \& Olino, 2020; Knutson et al., 2001).

From behavioural standpoint, Bechara, Damasio, and Damasio (1994) have divided the lowa Gambling Task into two categories: (i) healthy participants, and (ii) participants with lesion in the ventromedial prefrontal cortex, which is responsible for emotional responses to risk, reward, and decision making. The experiment was required participants to choose repeatedly from four cards, wherein two cards include wins monetary and two other cards include losses monetary, as depicted in Figure 3 (Antoine Bechara \& Damasio, 2005). Antoine Bechara and Damasio (2005) conducted the experiment to measure the emotional arousal of participants by using the galvanic skin response tool. In the case of normal participants, it has been noticed that the participants will begin to pick beneficial cards up from "Good" decks which include wins. While the participants with lesion sought to choose cards regardless if decks "Good" or "Bad" (Case \& Olino, 2020). The findings illustrated that the healthy participants have experienced a negative emotional response (i.e., sweating) which was warned them to picking up cards from the 'Bad decks'. On the opposite side of the spectrum, participants with damage in the ventromedial prefrontal cortex have not showed any changes on galvanic skin response tool whether they have chosen "Good" or "Bad" decks (Antoine Bechara \& Damasio, 2005). In addition, the findings showed that the reward process has highly effect decision-making process which related to reward and risk (Antoine Bechara \& Damasio, 2005; Antoine Bechara, Damasio, Tranel, \& Damasio, 1997; Maia \& McClelland, 2004). 


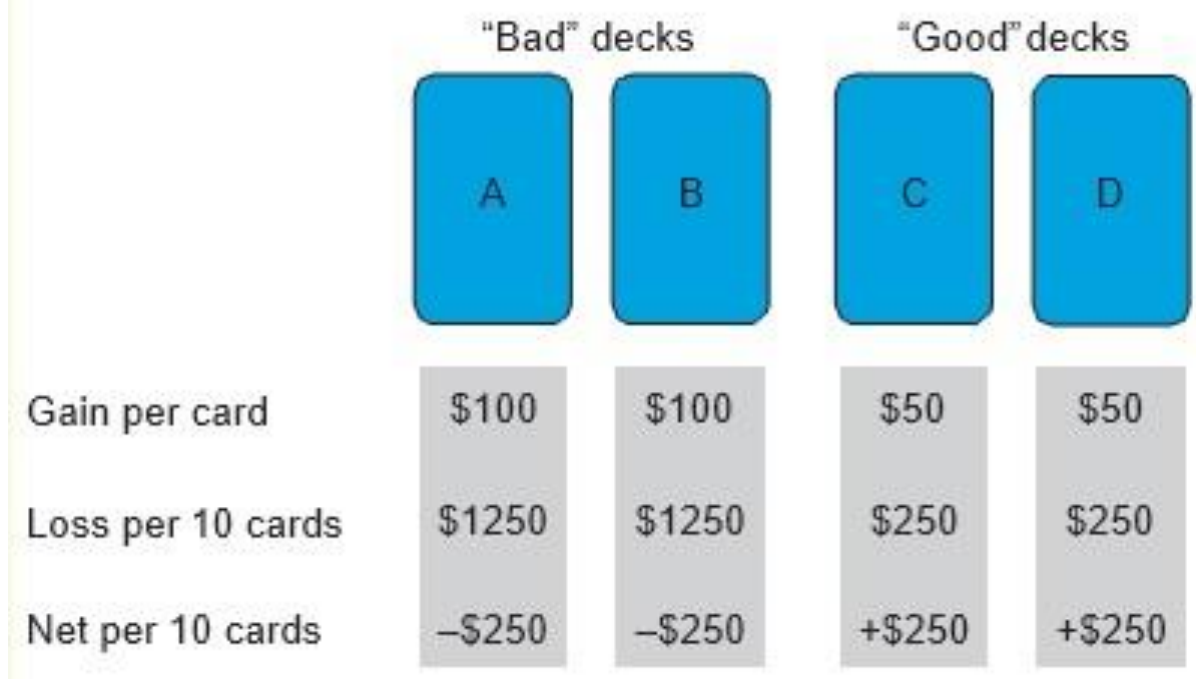

Fig. 3. The lowa Gambling Task (Antoine Bechara \& Damasio, 2005).

From neuroscientific standpoint, the activation in striatum which is located in the basal ganglia is related to the reward process activation by stimuli. The key functions of striatum (i.e., control movements and planning) play a central role in the rewards system, while striatum components (i.e., putamen, caudate nucleus, and nucleus accumbens) have a vital role in evaluating or consumer's expectations compared to actual rewards received (Knutson \& Wimmer, 2007; Padmala \& Pessoa, 2011) and the influence of social interactions on the striatum regions (Fliessbach et al., 2007; Lehner et al., 2017). Even the ventral tegmental area is part of the reward system, which neurotransmitter dopamine to other brain regions, enabling the modulation of decision-making and affecting in goal-seeking behaviour (Fields et al., 2007; Padmala \& Pessoa, 2011). Several neuroimaging studies, Galvan (2010); Geier, Terwilliger, Teslovich, Velanova, and Luna (2010) have used the fMRI technique to test individual developmental changes in the striatum, a region implicated in reward processing. The findings showed that the ventral striatum region plays a vital role of reward anticipation in individuals.

\section{The Differences in Emotional Interactions among Individuals Childhood and Adolescence}

Numerous researchers have studied the emotional interactions related to age, whether facial expressions or emotional words. Most studies focused on childhood (5-12 years old), adolescence (13-18 years old), and adult (19-28 years old). For example, emotional Go/No Go task, it has found that adolescents showed the greater interaction with negative emotional conditions compared with neutral and positive emotional conditions (CohenGilbert \& Thomas, 2013), and with fear faces compared with happy faces in an emotional Flanker task (Grose-Fifer, Rodrigues, Hoover, \& Zottoli, 2013). Consequently, adolescents are more likely to show preferential processing for emotional information, wherein it has supposed that the underlying reasons are increased exposure to emotional distractors and emotional disorders (Nelson et al., 2005).

Hare et al (2008) conducted a similar experiment using a neuroimaging technique such as magnetic resonance imaging (MRI); it has found that the increase in the amygdala activation in adolescence brain compared with children and adults, thereby, the rise in the amygdala activation and decrease in the ventrolateral prefrontal cortex activation was positively associated with target stimuli whether the fear or happy face, besides, the power 
connectivity of the amygdala and ventrolateral prefrontal cortex was linked to greater habituation of the amygdala activity to fearful faces targets in adolescence. Functional neuroimaging of emotion in young people has shown the recruitment of the same neural substrates in the amygdala-hippocampus complex, the inferior temporal lobe and anterior cingulate cortex (Vasa et al., 2011). However, subtle differences exist when comparing patterns of activation with adults, including greater the amygdala activation and more widespread activation during the encoding of emotional information (Nelson et al., 2003). Together, these studies suggest that emotional interactions undergo important maturational changes in childhood and adolescence.

\section{Ageing}

Ageing is not only associated with diseases but also with relatively high levels of emotional well-being. There is numerous evidence that supports the relationship between ageing and positivity effects on emotions, attention, memory, and perceptions, where older adults tend to pay more attention toward positive information and diminish negative information processing (Mather, 2016). Therefore, the preference of positive information by older adults is driven by identifying their priorities, which are based on present and related to emotion and satisfaction, which in turn enhance their well-being (Reed \& Carstensen, 2012). That means there is a difference in emotional processing between childhood, adolescence, and older adult, which allows an older adult to treat emotional challenges automatically (Dolcos, Katsumi, \& Dixon, 2014); consequently, emotional interactions of age differences indicate to relatively recorded mechanisms in the amygdala and enhanced mechanisms in the prefrontal cortex.

\section{Conclusion}

Implications of the research findings for theory and practice: The study thus concentrated on the variables of the neuromarketing field that influence consumer behaviour and play a key role in making a decision of consumers; Thereby, understanding the cognitive (e.g., attention and memory) and emotional (e.g., emotion) will aid advertisers, marketers, and even government and social initiatives to deal with needs of young adult and old people appropriately. Therefore, this will help advertisers, marketers, and government to create more effective social advertising campaigns for example but not limited to public health advertisements (anti-smoking campaigns) and social initiatives(e.g., the awareness of using a seat belt in the car and donation for poor people).

General Conclusion: Neuroscientific studies have proven that most decision-making is based primarily on emotional and not rational processing of information; consequently, emotional processes plays a vital role in influencing decision-making. For instance, a reward can contribute to distractions of emotion-attention if it does not correspond with the concerned task; besides, it had also found that the amygdala, medial prefrontal cortex, and ventromedial prefrontal cortex play a central role in processing of emotion which in turn influence decisionmaking process. While individuals with lesion in the ventromedial prefrontal cortex which responsible for emotional responses toward risk, reward, and decision-making are not good decision-makers. Motivational processes (e.g., approach and withdrawal behaviour) are playing a central role of decision-making, wherein motivational processes considered as the direction force that orient individuals in the task to accomplish their goals.

Also, it has found greater interaction by adolescents more than children and adults toward negative emotional conditions compared with neutral and positive in emotional 
Go/No-go task, and with the fear faces compared with happy faces in an emotional Flanker task. The reason may be adolescents exposed to greater emotional distractors and emotional disorders. This study contributes to the clear vision towards the importance of emotion through the critical study of the influence of emotion on decision-making and age. By neuroscience and psychology, researchers can study the responses of emotion to external stimuli; thereby, provide worthwhile information for researchers and scientists to satisfy the actual individuals' needs. So, this upcoming field should be focused on improving the general understanding of individuals' decision making and correct arbitrary assumptions by a few researchers or practitioners. Thus, it should use neuroscience and psychology to improve the well-being of society and people.

\section{Corresponding Author}

Nor Zafir Md Salleh

Azman Hashim International Business School (AHIBS), Universiti Teknologi Malaysia (UTM), Skudai, Johor 81310, Malaysia

Email: zafir@utm.my

\section{Acknowledgements}

The authors would like to thank Universiti Teknologi Malaysia (UTM), Azman Hashim International Business School (AHIBS) for supporting this study.

\section{References}

Adolphs, R. (2017). How should neuroscience study emotions? By distinguishing emotion states, concepts, and experiences. Social cognitive affective neuroscience, 12(1), 2431.

Agarwal, S. (2015). Introduction to Neuromarketing and Consumer Neuroscience. Journal of Consumer Marketing, 32(4), 302-303. doi:10.1108/jcm-08-2014-1118

Alsharif, A. H., Salleh, N. Z. M., \& Baharun, R. (2021). To Better Understand the Role of Emotional Processes in Decision-Making. International Journal of Academic Research in Economics and Management Sciences, 10(2), 49-67. doi:10.6007/IJAREMS/v10i2/9883

Alsharif, A. H., Salleh, N. Z. M., Baharun, R., Hashem E, A. R., Mansor, A. A., Ali, J., \& Abbas, A. F. (2021). Neuroimaging Techniques in Advertising Research: Main Applications, Development, and Brain Regions and Processes. Sustainability, 13(11), 6488-6513. doi:10.3390/su13116488

Alsharif, A. H., Salleh, N. Z. M., Baharun, R., \& Safaei, M. (2020). Neuromarketing approach: An overview and future research directions. Journal of Theoretical and Applied Information Technology, 98(7), 991-1001.

Alsharif, A. H., Salleh, N. Z. M., Baharun, R., \& Yusoff, M. E. (2021). Consumer Behaviour Through Neuromarketing Approach. Journal of Contemporary Issues in Business and Government, 27(3), 344-354. doi:10.47750/cibg.2021.27.03.048

Amthor, F. (2016). Neuroscience for dummies (2nd ed.). USA: John Wiley \& Sons.

Anderson, B. A. (2016). The attention habit: How reward learning shapes attentional selection. Annals of the New York Academy of Sciences, 1369(1), 24-39.

Anderson, B. A., Laurent, P. A., \& Yantis, S. (2013). Reward predictions bias attentional selection. Frontiers in Human Neuroscience, 7, 262. 
Bahrabad, M. R., \& Farrokhian, S. (2017). The Effect of Personality on Purchase Decisions Based on New Freud's Theories and Behavioral Theory in Mashhad.

Barrett, L. F. (2013). Psychological construction: The Darwinian approach to the science of emotion. Emotion Review, 5(4), 379-389.

Barrett, L. F. (2017). The theory of constructed emotion: an active inference account of interoception and categorization. Social cognitive affective neuroscience, 12(1), 1-23.

Bechara, A., \& Damasio, A. R. (2005). The somatic marker hypothesis: A neural theory of economic decision. Games and economic behavior, 52(2), 336-372.

Bechara, A., Damasio, H., \& Damasio, A., \& Anderson, S. (1994). Insensitivity to future consequences following damage to human prefrontal cortex. Cognition.

Bechara, A., Damasio, H., Tranel, D., \& Damasio, A. R. (1997). Deciding advantageously before knowing the advantageous strategy. Science, 275(5304), 1293-1295.

Belch, G. E., \& Belch, M. A. (2007). Advertising and promotion: An integrated marketing communications perspective (Seventh Edition ed.): McGraw-Hill International Edition.

Berridge, K. C. (1996). Food reward: brain substrates of wanting and liking. Neuroscience \& Biobehavioral Reviews, 20(1), 1-25.

Case, J. A., \& Olino, T. M. (2020). Approach and avoidance patterns in reward learning across domains: An initial examination of the Social lowa Gambling Task. Behaviour research therapy, 103547.

Cherubino, P., Maglione, A. G., Graziani, I., Trettel, A., Vecchiato, G., \& Babiloni, F. (2015). Measuring cognitive and emotional processes in retail: A neuroscience perspective. In Successful technological integration for competitive advantage in retail settings (pp. 76-92): IGI Global.

Cherubino, P., Martinez-Levy, A. C., Caratu, M., Cartocci, G., Di Flumeri, G., Modica, E., . . . Trettel, A. (2019a). Consumer behaviour through the eyes of neurophysiological measures: State-of-the-art and future trends. Computational Intelligence and Neuroscience.

Cherubino, P., Martinez-Levy, A. C., Caratu, M., Cartocci, G., Di Flumeri, G., Modica, E., . . . Trettel, A. (2019). Consumer Behaviour through the Eyes of Neurophysiological Measures: State-of-the-Art and Future Trends. Computational Intelligence and Neuroscience, 2019. doi:10.1155/2019/1976847

Cherubino, P., Martinez-Levy, A. C., Caratu, M., Cartocci, G., Di Flumeri, G., Modica, E., . . . Trettel, A. (2019b). Consumer behaviour through the eyes of neurophysiological measures: State of the art and future trends. Computational Intelligence and Neuroscience, 3(2), 01-41. doi:10.1155/2019/1976847

Chiew, K. S., \& Braver, T. S. (2011). Positive affect versus reward: emotional and motivational influences on cognitive control. Frontiers in Psychology, 2, 279.

Chiew, K. S., \& Braver, T. S. (2016). Reward favors the prepared: Incentive and taskinformative cues interact to enhance attentional control. Journal of Experimental Psychology: Human perception and performance, 42(1), 52.

Chow, Y., Masiak, J., Mikołajewska, E., Mikołajewski, D., Wójcik, G. M., Wallace, B., . . . Olajossy, M. (2018). Limbic brain structures and burnout- A systematic review. Advances in medical sciences, 63(1), 192-198. doi:10.1016/j.advms.2017.11.004

Cohen-Gilbert, J. E., \& Thomas, K. M. (2013). Inhibitory control during emotional distraction across adolescence and early adulthood. Child Development, 84(6), 1954-1966.

Damasio, A. R. (2003). Looking for Spinoza: Joy, sorrow, and the feeling brain: Houghton Mifflin Harcourt. 
Davidson, R. J. (2000). Affective style, psychopathology, and resilience: brain mechanisms and plasticity. American psychologist, 55(11), 1196.

Davidson, R. J. (2004). What does the prefrontal cortex "do" in affect: perspectives on frontal EEG asymmetry research. Biological psychology, 67(1-2), 219-234.

Davidson, R. J., \& Irwin, W. (1999). The functional neuroanatomy of emotion and affective style. Trends in cognitive sciences, 3(1), 11-21.

Dolan, R. J., \& Vuilleumier, P. (2003). Amygdala automaticity in emotional processing. Annals of the New York Academy of Sciences, 985(1), 348-355.

Dolcos, F., \& Denkova, E. (2014). Current emotion research in cognitive neuroscience: linking enhancing and impairing effects of emotion on cognition. Emotion Review, 6(4), 362375.

Dolcos, F., Katsumi, Y., Moore, M., Berggren, N., de Gelder, B., Derakshan, N., .. . Okon-Singer, H. (2019). Neural Correlates of Emotion-Attention Interactions: From Perception, Learning and Memory to Individual Differences and Training Interventions. Neuroscience Biobehavioral Reviews, 108, 559-601.

Dolcos, S., Katsumi, Y., \& Dixon, R. A. (2014). The role of arousal in the spontaneous regulation of emotions in healthy aging: a fMRI investigation. Frontiers in Psychology, 5, 681.

Ekman, P. (1999). Basic emotions. Handbook of cognition emotion, 98(45-60), 16.

Ekman, P. (2003). Sixteen enjoyable emotions. Emotion Researcher, 18(2), 6-7.

Eser, Z., Isin, F. B., \& Tolon, M. (2011). Perceptions of marketing academics, neurologists, and marketing professionals about neuromarketing. Journal of Marketing Management, 27(7), 854-868. doi:10.1080/02672571003719070

Fields, H. L., Hjelmstad, G. O., Margolis, E. B., \& Nicola, S. M. (2007). Ventral tegmental area neurons in learned appetitive behavior and positive reinforcement. Annu. Rev. Neurosci., 30, 289-316.

Fliessbach, K., Weber, B., Trautner, P., Dohmen, T., Sunde, U., Elger, C. E., \& Falk, A. (2007). Social comparison affects reward-related brain activity in the human ventral striatum. Science, 318(5854), 1305-1308.

Frijda, N. H. (1986). The emotions: Cambridge University Press.

Galvan, A. (2010). Adolescent development of the reward system. Frontiers in Human Neuroscience, 4(6), 1-9.

Geier, C., Terwilliger, R., Teslovich, T., Velanova, K., \& Luna, B. (2010). Immaturities in reward processing and its influence on inhibitory control in adolescence. Cerebral Cortex, 20(7), 1613-1629.

Genco, S., Pohlmann, A., \& Steidl, P. (2013). Neuromarketing for dummies. USA: John Wiley \& Sons.

Gilbert, A. M., \& Fiez, J. A. (2004). Integrating rewards and cognition in the frontal cortex. Cognitive, Affective, \& Behavioral Neuroscience, 4(4), 540-552.

Gordon, W. (2006). What do consumers do emotionally with advertising? Journal of Advertising Research, 46(1), 2-10.

Grose-Fifer, J., Rodrigues, A., Hoover, S., \& Zottoli, T. (2013). Attentional capture by emotional faces in adolescence. Advances in cognitive psychology, 9(2), 81.

Hare, T. A., Tottenham, N., Galvan, A., Voss, H. U., Glover, G. H., \& Casey, B. (2008). Biological substrates of emotional reactivity and regulation in adolescence during an emotional go-nogo task. Biological Psychiatry, 63(10), 927-934.

Harrison, T., Waite, K., \& White, P. (2006). Analysis by paralysis: the pension purchase decision process. The International Journal of Bank Marketing, 24(1), 5. 
Higgins, E. T. (1998). Promotion and prevention: Regulatory focus as a motivational principle. In Advances in experimental social psychology (Vol. 30, pp. 1-46): Elsevier.

$\mathrm{Hu}, \mathrm{Z} .$, \& Nasiry, J. (2018). Are markets with loss-averse consumers more sensitive to losses? Management Science, 64(3), 1384-1395.

Jacobs, R. H., Renken, R., Aleman, A., \& Cornelissen, F. W. (2012). The amygdala, top-down effects, and selective attention to features. Neuroscience \& Biobehavioral Reviews, 36(9), 2069-2084.

Kahneman, D. (2011). Thinking, fast and slow: Macmillan.

Kajic, I., Schröder, T., Stewart, T. C., \& Thagard, P. (2019). The semantic pointer theory of emotion: Integrating physiology, appraisal, and construction. Cognitive Systems Research, 58, 35-53.

Knutson, B., Adams, C. M., Fong, G. W., \& Hommer, D. (2001). Anticipation of increasing monetary reward selectively recruits nucleus accumbens. Journal of Neuroscience, 21(16), RC159-RC159.

Knutson, B., \& Wimmer, G. E. (2007). Splitting the difference: how does the brain code reward episodes? Annals of the New York Academy of Sciences, 1104(1), 54-69.

Krawczyk, D. C., Gazzaley, A., \& D'Esposito, M. (2007). Reward modulation of prefrontal and visual association cortex during an incentive working memory task. Brain Research, $1141,168-177$.

Lang, P. J., \& Bradley, M. M. (2008). Cortex-Reflex Connections Appetitive and Defensive Motivation Is the Substrate of Emotion. 51.

Langleben, D. D., Loughead, J. W., Ruparel, K., Hakun, J. G., Busch-Winokur, S., Holloway, M. B., ... Lerman, C. (2009). Reduced prefrontal and temporal processing and recall of high "sensation value" ads. Neuroimage, 46(1), 219-225.

Lazarus, R. S. (2006). Stress and emotion: A new synthesis. London, UK: Springer Publishing Company.

LeDoux, J. (1998). The emotional brain: The mysterious underpinnings of emotional life: Simon and Schuster.

Lehner, R., Balsters, J. H., Herger, A., Hare, T. A., \& Wenderoth, N. (2017). Monetary, food, and social rewards induce similar Pavlovian-to-instrumental transfer effects. Frontiers in Behavioral Neuroscience, 10, 247.

Maia, T. V., \& McClelland, J. L. (2004). A reexamination of the evidence for the somatic marker hypothesis: what participants really know in the lowa gambling task. Proceedings of the National Academy of Sciences, 101(45), 16075-16080.

Mather, M. (2016). The affective neuroscience of aging. Annual review of psychology, 67.

Montazeribarforoushi, S., Keshavarzsaleh, A., \& Ramsøy, T. Z. (2017). On the hierarchy of choice: An applied neuroscience perspective on the AIDA model. Cogent Psychology, 4(1), 1363343.

Nábrády, M. (2005). Emotion theories and transactional analysis emotion theory: A comparison. Transactional Analysis Journal, 35(1), 68-77.

Nelson, E. E., Leibenluft, E., McClure, E. B., \& Pine, D. S. (2005). The social re-orientation of adolescence: a neuroscience perspective on the process and its relation to psychopathology. Psychological Medicine, 35(2), 163.

Nelson, E. E., McClure, E. B., Monk, C. S., Zarahn, E., Leibenluft, E., Pine, D. S., \& Ernst, M. (2003). Developmental differences in neuronal engagement during implicit encoding of emotional faces: An event-related fMRI study. Journal of Child Psychology and Psychiatry, 44(7), 1015-1024. 
Öhman, A., Carlsson, K., Lundqvist, D., \& Ingvar, M. (2007). On the unconscious subcortical origin of human fear. Physiology \& Behavior, 92(1-2), 180-185.

Padmala, S., \& Pessoa, L. (2011). Reward reduces conflict by enhancing attentional control and biasing visual cortical processing. Journal of Cognitive Neuroscience, 23(11), 34193432.

Page, G. (2012). Scientific realism: What neuromarketing can and can't tell us about consumers. International Journal of Market Research, 54(2), 287-290. doi:10.2501/IJMR-54-2-287-290

Papez, J. W. (1937). A proposed mechanism of emotion. Archives of Neurology Psychiatry, 38(4), 725-743. doi:10.1001/archneurpsyc.1937.02260220069003

Pessoa, L. (2009). How do emotion and motivation direct executive control? , 13(4), 160-166.

Pessoa, L. (2013). The cognitive-emotional brain: From interactions to integration. London, UK: MIT press.

Pessoa, L. (2014). Attention, motivation, and emotion. In. London, England: Oxford

Ramsoy, T. (2014). An Introduction to Consumer Neuroscience \& Neuromarketing Retrieved from

https://www.coursera.org/learn/neuromarketing/lecture/FTWBU/introduction-tothis-course

Raymond, J. (2009). Interactions of attention, emotion and motivation. Progress in brain research, 176, 293-308.

Reed, A. E., \& Carstensen, L. L. (2012). The theory behind the age-related positivity effect. Frontiers in Psychology, 3, 339.

Shafer, A., Iordan, A., Cabeza, R., \& Dolcos, F. (2011). Brain imaging investigation of the memory-enhancing effect of emotion. Journal of Visualized Experiments(51), e2433.

Siddharthan, A., Cherbuin, N., Eslinger, P. J., Kozlowska, K., Murphy, N. A., \& Lowe, L. (2018). WordNet-feelings: a linguistic categorisation of human feelings. arXiv preprint arXiv:1811.02435.

Simson, A. K. (2010). Neuromarketing, emotions, and campaigns. Yayımlanmamış Yüksek Lisans Tezi, Copenhagen Business School Master of Social Science.

Torrico, T. J., \& Abdijadid, S. (2019). Neuroanatomy, Limbic System. Retrieved from https://www.ncbi.nlm.nih.gov/books/NBK538491/\#_NBK538491_ai_

Tracy, J. L., \& Randles, D. (2011). Four models of basic emotions: a review of Ekman and Cordaro, Izard, Levenson, and Panksepp and Watt. Emotion Review, 3(4), 397-405.

Vasa, R. A., Pine, D. S., Thorn, J. M., Nelson, T. E., Spinelli, S., Nelson, E., . . Mostofsky, S. H. (2011). Enhanced right amygdala activity in adolescents during encoding of positively valenced pictures. Developmental Cognitive Neuroscience, 1(1), 88-99.

Vecchiato, G., Astolfi, L., Fallani, F. D. V., Cincotti, F., Mattia, D., Salinari, S., . . Babiloni, F. (2010). Changes in brain activity during the observation of TV commercials by using EEG, GSR and HR measurements. Brain Topography, 23(2), 165-179.

Vermaak, M., \& de Klerk, H. M. (2017). Fitting room or selling room? Millennial female consumers' dressing room experiences. International Journal of Consumer Studies, 41(1), 11-18.

Vuilleumier, P. (2005). How brains beware: neural mechanisms of emotional attention. Trends in cognitive sciences, 9(12), 585-594. 